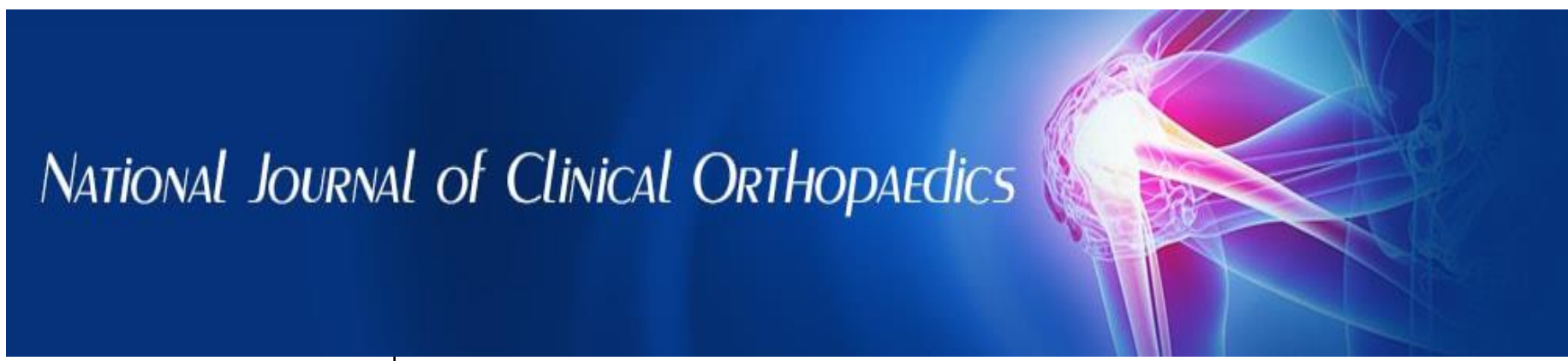

ISSN (P): 2521-3466

ISSN (E): 2521-3474

(C) Clinical Orthopaedics www.orthoresearchjournal.com 2021; 5(3): 93-95

Received: 16-05-2021

Accepted: 18-06-2021

Dr. Siddaram Patil N

Professor HOD, Anil

Neerukonda Hospital, NRI

Institute of Medical Sciences,

Sangivalasa. Visakhapatnam.

Andhra Pradesh, India

Dr. Shiv Sandeep

Assistant Professor, NRI

Institute of Medical Sciences

Sangivalasa, Vishakapatnam

Andhra Pradesh, India

Dr. Chinni Ganesh

Anil Neerukonda Hospital, NRI

Institute of Medical Sciences,

Sangivalasa. Visakhapatnam.

Andhra Pradesh, India

\section{Intramedullary enchondroma of distal femur treated with curettage in 31 year old female: A case report}

\author{
Dr. Siddaram Patil N, Dr. Shiv Sandeep and Dr. Chinni Ganesh
}

DOI: $\underline{\text { https://doi.org/10.33545/orthor.2021.v5.i3b.297 }}$

\section{Abstract}

Introduction: Enchondroma is a benign tumor, commonly seen in long short bones. An enchondroma is a type of non-cancerous bone tumor that begins in cartilage. Cartilage is the gristly connective tissue from which most bones develop. Cartilage plays an important role in the growth process. There are many different types of cartilage in the body. Enchondroma is a benign tumor, commonly seen in long short bones.

Aim: Generalafter skeletal maturity, enchondroma do not grow and rarely cause pain. Endosteal scalloping may occur with enchondroma. Reporting this unusual location, Intra-Medullary and long bone, in Femur distal third marrow, in our case.

Keywords: intramedullary enchondroma, distal femur treated, curettage, 31 year old female

\section{Introduction}

Enchondroma (chondromyxoma) is a solitary intramedullary benign tumour composed of matured cartilage, that is usually found in the short tubular bones of hands and feet. Enchondromas consists of 3-10\% of all bone tumours and $12-24 \%$ of benign tumours. In $50 \%$ cases it is found in bones of hand and younger age group. We report rare case of enchondroma in 31 year old patient at distal femur treated with curettage and sent for histopathological examination.

\section{Case Presentation}

A 31 year female presented to our hospital with a history of pain in right knee and discomfort while walking since 2 months following slip and fall at home with twisted knee. Patient gave history of constant dull aching type pain insidious in onset, moderate degree, non-radiating with on and off swelling. Pain aggrevated on standing and walking and relieved on taking rest and analgesics. The general examination was unremarkable with no significant proximal lymphadenopathy and distal neurovascular defecits. Local examination reveled positive lachmann test with full range of movement with no skin changes and no local rise of temperature.

\section{Surgical Procedure}

The patient under spinal anesthesia, placede in supine position, a lateral incision was taken on distal femur, lesion was exposed and tumour was removed through a lateral bone window and through curettage was done. Tumour curetted were sent for histopathological analysis. Static quadriceps and knee range of movement exercises were started on day one postoperatively. Sutures were removed after 2 weeks and allowed to do partial weight bearing from 4 weeks gradually increasing to complete weight bearing over next 1 month. At the latest follow up the patient was symptom free and there was no evidence of any recurrence.
Corresponding Author: Dr. Shiv Sandeep Assistant Professor, NRI Institute of Medical Sciences Sangivalasa, Vishakapatnam Andhra Pradesh, India 

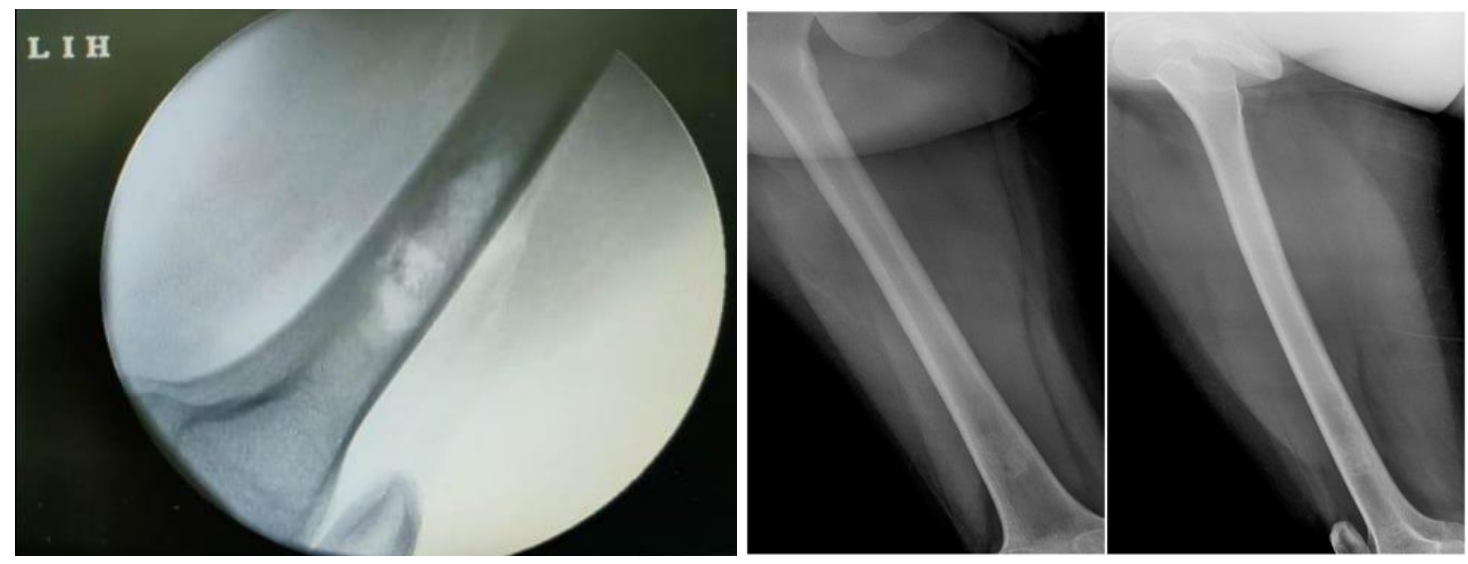

Fig 1: X-Ray of Femur full length, shows tumor at distal third itra-Medullary.

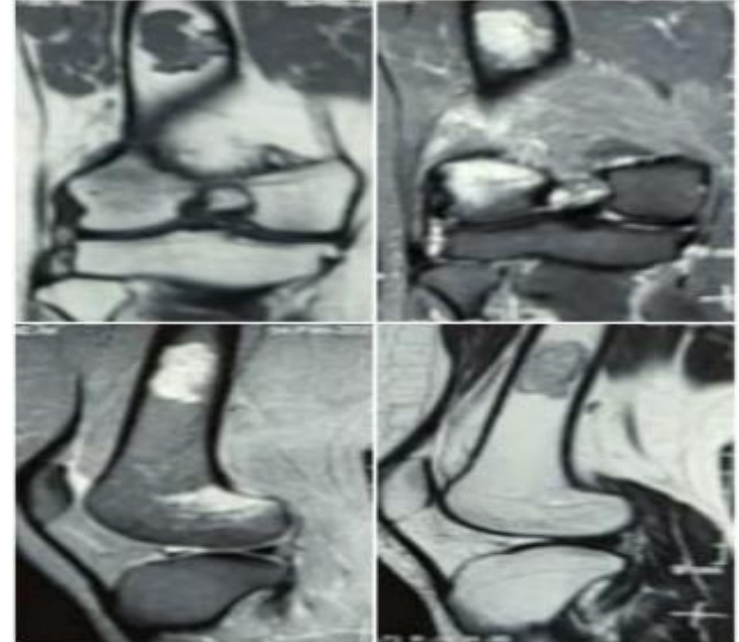

Fig 2: MRI showed Incidentally noted altered signal intensity focal lesion measuring 3.1 (CC) x 13 (AP) x $19 \mathrm{~cm}$ involving the distal shaft of the femur in the intramedullary location, without any perilesional marrow edema noted - Enchondroma

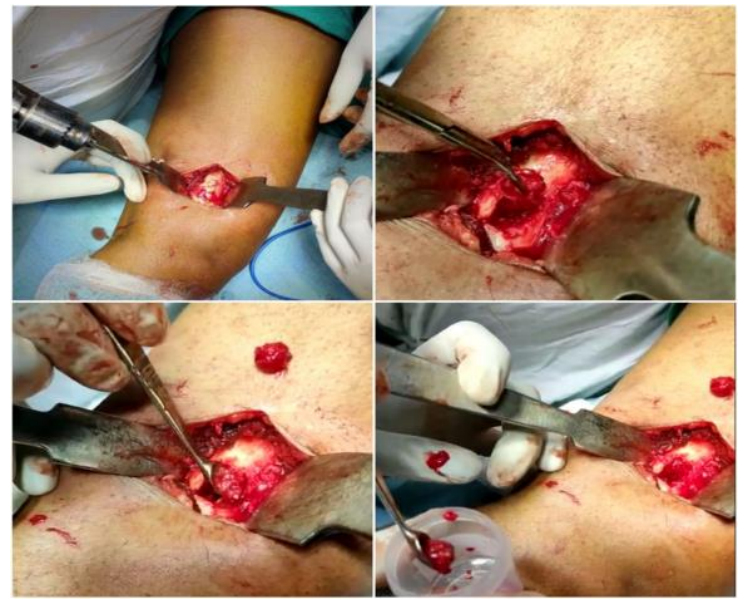

Fig 3: Intra -Medullary excison with curettage

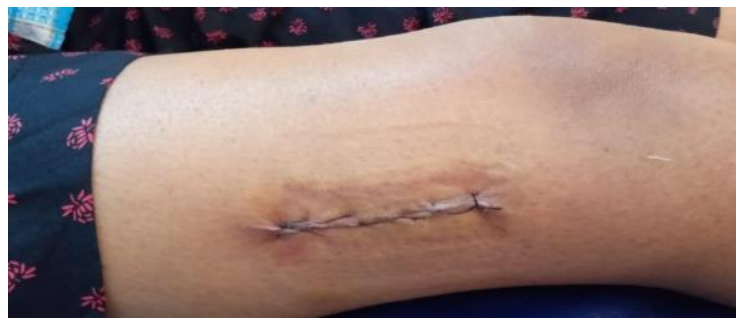

Fig 4: Post -Op clinically

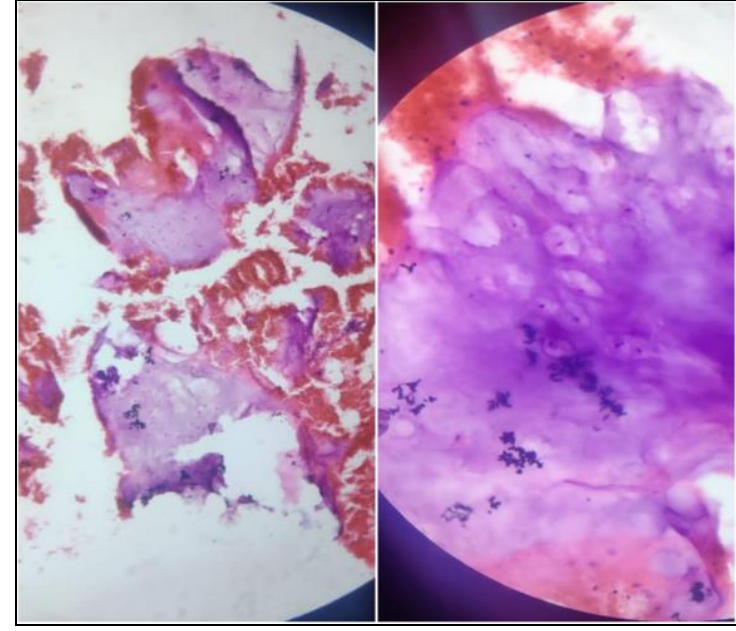

Fig 5: Histopathological report showed mature cartiaiginious cap over mature bone, confirming the diagnosis. At the latest follow up the patient was symptom free and there was no evidence of any recurrence.

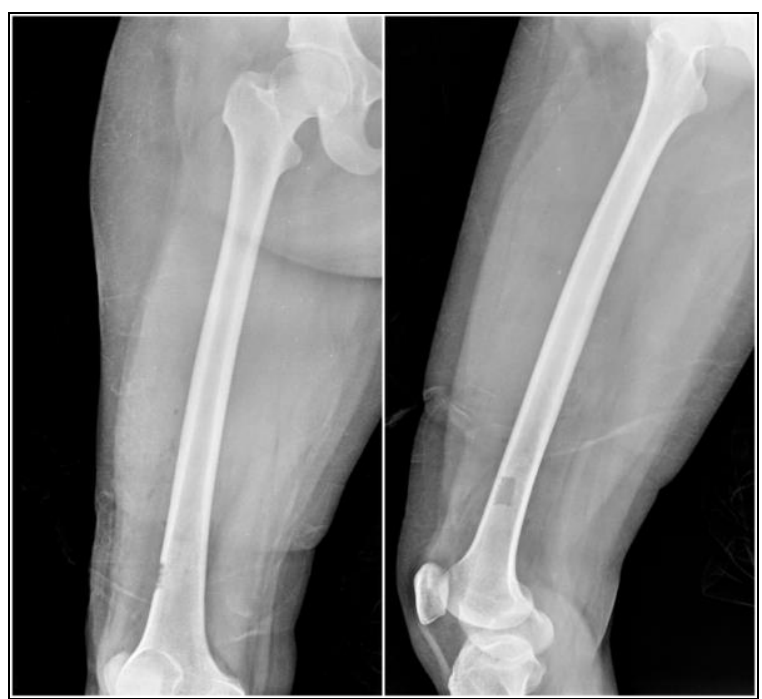

Fig 6: Follow up. Radiological examination with $\mathrm{x}$ ray of distal femur revealed a small well demarcated lobulated lytic subcondral lesion with cortical thinning in distal femur with intralesional calcification without extension in joint.

\section{Discussion}

Presence of pathology in distal femur arouses suspicion of various other differential diagnosis like giant cell tumour, aneurismal bone cyst, chondroblastoma, chondrosarcoma, hence Enchondroma should also be kept in mind. The enchondroma healed without recurrence. Usually either allograft or allograft is 
used to fill the defect, in our case it is one of the rarest reported cases of distal femur enchondroma where only curettage was used successfully. Enchondromas are usually more common between 10-50 years of age, and most common locations are small tubular bones of hand and feet. Our case is rare in the sense as it was found at rare location of distal femur. The differentiation of benign from malignant cartilaginous tumours is one of the most difficult problems in bone pathology. In our case which is clinically normal, mri report showing incidental diagnosis of Enchondroma and finally the confirmatory diagnosis on histopathological examination came out to be Enchondroma. It is often diffucult to distinguish enchondromas from low grade chondrosarcomas.

\section{Conclusion}

This case study reports the presentation of atypical enchondroma presenting in a 31 year old female at a rare intramedullary site of distal femur in long bone. Enchondroma was differentiated from malignant tumour and other differential diagnosis and treated by curettage. This case study will help future researchers to study enchondromas with atypical character, differentiate it from malignancy and try out other combinations of newer modalities of treatment.

\section{References}

1. Walden MJ, Murphy MD, Vidal JA. Incidental enchondromas of the knee. AJR Am Roentgenol 2008;190(6):1611-15.

2. Edward M, Jewusiak, Kenneth F Spence, Kenneth W Sell. Solitary Benign Enchondroma Of The Long Bones Of The Hand . JBJS Am 1971;53(8):1587-1590.

3. Campbells Operative Orthopaedics, 12 th edition, Tumours. Benign Bone Tumours And Nonneoplastic Conditions Simulating Bone Tumours, S Terry Canale, James H Beaty, 1,865 .

4. Tureks Orthopaedics: Principles and their Application, 4th edition, Samuel L Turek, 1, 599.

5. Kendell SD, Collons MS, Arkins MC, Sundaram M, Tinny KK. Radiographic differentiation of enchondroma from low grade chondrosarcoma in the fibula . Skeletal Radiology 2004;33(8):1432-2161. 